\title{
Caracterização e atividade antibacteriana de óleos essenciais de plantas condimentares e medicinais contra Staphylococcus aureus e Escherichia coli
}

\begin{abstract}
MILLEZI A.F."; BAPTISTA N.N.2; CAIXETA D.S. 3; ROSSONI D.F.4; CARDOSO M.G.5; PICCOLI R.H. ${ }^{2}$ ${ }^{1}$ Departamento de Ciências Biológicas, Setor de Microbiologia Agrícola -Universidade Federal de Lavras, 37200000, Lavras, Brasil, amillezi@yahoo.com.br, ${ }^{2}$ Departamento de Ciência dos Alimentos -Universidade Federal de Lavras - 37200-000, Lavras, Brasil, ${ }^{3}$ Departamento de Engenharia Sanitária e Ambiental - Universidade Federal de Mato Grosso - 78060-900, ${ }^{4}$ Departamento de Ciências Exatas - Universidade Federal de Lavras - 37200000, Lavras, Brasil, ${ }^{5}$ Departamento de Química - Universidade Federal de Lavras - 37200-000, Lavras, Brasil
\end{abstract}

RESUMO: Os óleos essenciais são metabólitos secundários vegetais com propriedades biológicas diferenciadas, dentre elas a atividade contra microrganismos, sendo de importante interesse para a indústria de alimentos. As concentrações mínimas inibitórias (CMI) desses óleos para diversas bactérias devem ser determinadas. As CMI variam de acordo com o óleo utilizado, dos compostos majoritários e do tipo de bactéria. Nesta pesquisa, os óleos essenciais das plantas Satureja montana L., Cymbopogon nardus L. e Citrus limonia Osbeck foram caracterizados quimicamente e determinada a CMI sobre as bactérias Staphylococcus aureus ATCC 2592 e Escherichia coli ATCC 25922. A CMI para todos os óleos contra E. coli foi 1,5\%, já $S$. aureus foi sensível a partir da concentração de 5,0\% do óleo essencial de $S$. montana e $1,5 \%$ foi a CMI obtida quando utilizados os óleos essenciais das outras espécies estudadas. $\mathrm{Na}$ constituição química os componentes majoritários para os óleos de S. montana, C. narduse C. limonia Osbeck foram respectivamente o timol, citronelal e limoneno.

Palavras-chave: antimicrobianos naturais, bactérias, óleos essenciais

ABSTRACT: Essential oil characterization and its antibacterial activity from culinary and medicinal plants against Staphylococcus aureus and Escherichia coli. Essential oils are plant secondary metabolites with different biological properties, such as action against microorganisms, being majorly important to the food industry. The minimal inhibitory concentrations (CMI) of these oils for several bacteria should be determined. CMls vary according to the oil used, the major compounds and the phenotypic and genotypic characteristics of the bacteria. In this research, the essential oils of the plants Satureja montana L., Cymbopogon nardus L. and Citrus limonia Osbeck were chemically characterized, and CMI was determined for the Staphylococcus aureus ATCC 2592 and Escherichia coli ATCC 25922 bacteria. The CMI for all oils against $E$. coli was at $1.5 \%$, and $S$. aureus was sensitive to the $5.0 \%$ concentration of the S. montana oil, and the CMI achieved was equivalent to $1.5 \%$ when essential oils of other plants were used. In the chemical composition, the major components for the S. montana, $C$. nardus and C.limonia Osbeck oils were thymol, citronellal and limonene, respectively.

Keywords: natural antimicrobial, bacteria, essential oils

\section{INTRODUÇÃO}

Os óleos essenciais (OEs) são definidos como substâncias complexas voláteis, lipofílicas, geralmente odoríferas e líquidas, oriundas do metabolismo secundário de vegetais. Estes podem ser aplicados em vários segmentos, como antibacterianos, antivirais, antifúngicos, inseticidas e contra o ataque de herbívoros, bem como nos setores de higiene pessoal, perfumaria, cosmética, com um mercado mundial gerando em torno de US\$ 1,8 bilhão. A participação do Brasil corresponde a apenas $0,1 \%$ deste valor sendo $80 \%$ referente ao comércio de óleo de laranja (Simões \& Spitzer, 2004; Costa, 2008).

As propriedades antimicrobianas dos OEs de plantas condimentares e medicinais têm despertado interesse pela perspectiva de constituírem uma alternativa quanto à utilização de aditivos químicos em alimentos. Nos últimos anos tem sido relatado que alguns OEs são capazes de inibir bactérias de origem alimentar e prolongar a

Recebido para publicação em 03/05/2011

Aceito para publicação em 28/11/2012

Rev. Bras. PI. Med., Campinas, v.15, n.3, p.373-379, 2013. 
vida de prateleira de alimentos processados (Kim et al., 1995; Smith-Palmer et al., 1998). Atualmente várias pesquisas têm investigado OEs como antimicrobianos contra diversas bactérias. Os estudos também enfocam a constituição dessas substâncias relatando a existência de diferenças na composição química entre os óleos extraídos de espécies distintas ou variedades. Estas variações tendem a influenciar a atividade antimicrobiana dos óleos e são geralmente em função de fatores como: propriedades geneticamente determinadas, idade da planta, sazonalidade, disponibilidade hídrica, temperatura do ambiente onde a planta se desenvolveu, nutrientes disponíveis no solo, altitude e radiação UV (Martins etal., 2003; GobboNeto \& Lopez, 2007). Além disso, muitas vezes, os constituintes dos OEs encontram-se em pequenas concentrações ou sua efetividade ocorre por ação sinergística com vários outros compostos, dificultando os processos de purificação, ou a obtenção dos diferentes compostos puros.

Cymbopogon nardus, popularmente conhecido como capim-citronela é uma importante planta aromática, utilizada em soluções repelentes contra insetos e no setor de perfumaria. (Castro \& Ramos, 2003). Óleos essenciais extraídos de folhas de desse vegetal obtidos na Indonésia, tem como compostos majoritários o citronelal, citronelol e geraniol (Oliveira et al., 2010; Andrade, 1996), sendo bastante utilizados como calmante e no combate a disfunções digestivas (Craveiro et al., 1981; Castro \& Ramos, 2003).

Satureja montana é comumente conhecida como segurelha de inverno ou segurelha montanhesa é forte erva aromática e tem sido usada a centenas de anos como condimento de alimentos e chás, utilizada na comida mediterrânea, principalmente como tempero de carnes e peixes (Prieto et al., 2007; Silva et al., 2009). Na medicina tradicional e homeopática a segurelha de inverno é utilizada em várias enfermidades, principalmente digestiva, como cólica e diarréia; estimulantes, espectorantes, carminativos, anticatarraise afrodisíaco (Ćetkovićet al., 2007; Oliveira et al., 2011). Os compostos aromáticos, variando entre carvacrol, cimeno e timol, constituem a maioria do óleo essencial de Satureja montana (segurelha) (Cávar et al., 2008; Fraternale et al., 2007; Oliveira et al., 2011).

Citrus limonia Osbeck, conhecido popularmente como limão-cravo ou limão rosa, é produzido em larga escala no Brasil. As folhas de C. limonia são utilizadas para infusões no combate de resfriados e coriza, além disso, o suco é utilizado na medicina alternativa para tratamento de problemas gastrointestinais e contra infecções bacterianas (Spethmann, 2004). Na constituição do $\mathrm{OE}$ de $C$. limonia o limoneno é o composto majoritário (aproximadamente 95\%) (Fisher \& Phillips, 2006). Dentre as bactérias contaminantes de alimentos e relatadas como agentes causadores de doenças veiculadas por alimentos, pode-se mencionar Escherichia coli e Staphylococcus aureus. A bactéria $S$. aureus é responsável por causar surtos de toxinose, sendo que o principal hábitat em humanos e animais é a mucosa naso-faríngea, onde forma parte da microbiota normal (Fueyoet al., 2005). E. coli é agente causador de gastrenterites, a contaminação de se dá principalmente por contato com material fecal ou contato com superfícies contaminadas (Nascimento \& Stamford, 2000). Ambos os microrganismos são responsáveis por inúmeros casos de Doenças Veiculadas por Alimentos (DVAs).

Diante do exposto, o objetivo desse estudo foi avaliar a atividade antibacteriana dos óleos essenciais de S. montana, C. nardus e C. limonia determinando a concentração mínima inibitória $(\mathrm{CMI})$ sobre $S$. aureus e E. coli.

\section{MATERIAIS E MÉTODOS}

O experimento foi realizado em duas etapas. Na primeira, foi realizada a extração e caracterização dos óleos essenciais de S. Montana L., C. nardus L.e C. limonia Osbeck, na segunda, foi determinada a atividade antibacteriana dos óleos essenciais.

\section{Microrganismos utilizados e padronização do inóculo}

As bactérias utilizadas no experimento foram Staphylococcus aureus ATCC 25923 e Escherichia coli ATCC 25922. A padronização do inóculo foi realizada mediante curva de crescimento, relacionando-se absorbância a $600 \mathrm{~nm}$ e UFC $\mathrm{mL}^{-1}$. Utilizou-se a técnica de plaqueamento em superfície em meio de cultivo Agar Triptona de Soja (TSA) e o cultivo do microrganismo em caldo infusão cérebro coração (BHI). As leituras de absorbância foram realizadas periodicamente, até obterem-se $10^{8} \mathrm{UFC} \mathrm{mL}^{-1}$.

\section{Material vegetal}

Foram utilizadas folhas de C. nardus, obtidas no Horto de Plantas Medicinais de UFLA. As coletas foram realizadas das 8 às 9 horas da manhã, em dias ensolarados e ausentes de chuva, no mês de março de 2010, sob temperatura de, aproximadamente, $20^{\circ} \mathrm{C}$ (Martins et al., 1994). As folhas secas de S. montana foram adquiridas no Mercado municipal de São Paulo - SP e as cascas de C. limonia foram coletadas das 8 às 9 horas da manhã, em dias ensolarados e ausentes de chuva, no mês de março de 2010 no pomar da UFLA. As folhas de $C$. nardus e cascas de C. limonia, ambas coletadas frescas, foram secas em estufa por 72 horas a $40{ }^{\circ} \mathrm{C}$ para posterior extração dos óleos essenciais. 


\section{dos OEs}

Extração e determinação do rendimento

O processo de extração dos OEs foi realizado empregando-se o método de hidrodestilação, em aparelho de Clevenger modificado. Foram utilizadas $300 \mathrm{~g}$ da amostra (S. montana), $200 \mathrm{~g}$ (C. citratus) e $200 \mathrm{~g}$ (C. limonia). Após 2 horas de extração, o óleo obtido foi coletado e centrifugado, a $321,8 \times \mathrm{G}$, por 5 minutos, em centrífuga Fanem-Baby I Mod 206, e acondicionado em frasco de vidro revestido com papel alumínio, previamente esterilizado (Guimarães et al., 2008). A extração foi realizada em duplicata.

Foi realizada a pesagem dos frascos utilizados para acondicionar os óleos essenciais antes e após a adição dos mesmos, objetivando-se obter a massa extraída em gramas. A partir da massa obtida para extração e da umidade do material vegetal, realizados, ambos, em três repetições, os rendimentos dos óleos essenciais extraídos foram calculados e expressos em base livre de umidade (\% v/p BLU).

\section{Determinação da unidade}

Para a determinação da umidade do material vegetal, $5 \mathrm{~g}$ de folhas frescas de $S$. montana e $C$. nardus e $5 \mathrm{~g}$ de cascas de $C$. limonia, separadamente, foram imersas em $80 \mathrm{~mL}$ de ciclohexano em balão volumétrico com capacidade de $250 \mathrm{~mL}$ que foi acoplado ao condensador com coletor volumetricamente graduado. A temperatura de aquecimento do balão foi de $100^{\circ} \mathrm{C}$ em manta aquecedora. Após 2,5 horas, o volume de água presente nas folhas foi quantificado. A umidade foi calculada a partir do teor de água contido em $300 \mathrm{~g}$ da amostra (S. montana), $200 \mathrm{~g}$ (C. citratus) e 200 g (C. limonia) (Pimentel et al., 2006).

\section{Quantificação dos constituintes dos OEs}

A avaliação qualitativa dos OE foi realizada por cromatografia em fase gasosa acoplada ao espectrômetro de massa (CG/EM), utilizando o aparelho Shimadzu modelo GCMS - QP2010 Plus. As condições operacionais foram: coluna capilar de sílica fundida com fase ligada DB5 (30m X 0,25 mm), o gás carreador utilizado foi o hélio com vazão de $1 \mathrm{~mL} / \mathrm{min}$, temperaturas de $220^{\circ} \mathrm{C}$ no injetor e 240 ${ }^{\circ} \mathrm{C}$ no detector, programação da coluna, temperatura inicial $40^{\circ} \mathrm{C} \mathrm{com}$ acréscimo de $3^{\circ} \mathrm{C}$ a cada minuto. Os compostos foram identificados por comparações com espectros existentes na biblioteca (Wiley 8 e FFNSC 1.2) e pelo índice Kovat's (Adams, 2007).

\section{inibitória}

Determinação da concentração mínima

A concentração mínima inibitória dos OEs foi determinada através da técnica de DiscoDifusão conforme NCCLS (M7-A6) (NCCLS, 2003) com modificações. Adicionou-se uma alíquota da suspensão padronizada dos microrganismos ao meio de cultura TSA, à temperatura de aproximadamente $45^{\circ} \mathrm{C}$, obtendo-se concentração final de $10^{8}$ UFC $\mathrm{mL}^{-1}$. A mistura foi homogeneizada e vertida imediatamente em placas de Petri sendo que a CMI foi determinada separadamente para cada bactéria em estudo. Os OEs foram diluídos em dimetilsufóxido (DMSO 0,2\%) nas concentrações 0,0 (controle), 1,5; 2,5; 5,0; 10,0; 15,0; 25,0 e 50,0\%. Foram utilizados $5 \mu \mathrm{L}$ de óleo essencial para a aplicação em discos de papel filtro ( $\left.n^{\circ} 103\right)$ medindo $6 \mathrm{~mm}$ de diâmetro. Os discos foram colocados sob as placas com meio de cultura TSA contendo os microrganismos. As placas foram incubadas a 37 ${ }^{\circ} \mathrm{C}$, por 24 horas. O controle negativo foi preparado usando somente o solvente (DMSO 0,2\%). A CMI foi avaliada utilizando paquímetro para a medição dos halos de inibição.

\section{RESULTADO E DISCUSSÃO}

No Brasil há várias pesquisas que relatam a existência de diferentes características químicas entre os óleos essenciais de espécies distintas e até mesmo entre espécies iguais, porém cultivadas em diferentes regiões geográficas do globo terrestre. Nas condições utilizadas nesse estudo para extração dos óleos essenciais de $C$. nadus, $S$. montana e C. limonia, além da caracterização química, observou-se as variações no rendimento e umidade. $O$ teor de umidade das folhas secas de C. nardus e de S. Montana foi de 9,0\% e 8,0\%, respectivamente. Para C. limonia obteve-se $7 \%$, enquanto que o rendimento dos óleos foi $1,24 \%$, $1,48 \%$ e $1,85 \% \%$, respectivamente.

Resultados distintos dos obtidos no presente estudo, em relação ao rendimento dos OEs foram encontrados em outros estudos. Marco et al. (2007) examinaram o rendimento do óleo essencial de $C$. nardus cultivados em diferentes espaçamentos, altura e épocas de cortes,encontraram resultados variando de $3,52 \%$ a $4,18 \%$ de OE na matéria seca. O rendimento de óleo essencial de $S$. montana foi bastante satisfatório $(1,25 \%)$, quando comparado a $0,47 \%$ ao obtido por Oliveira et al. (2011). Segundo Burt (2004), variações no rendimento do OE entre plantas pertencentes à mesma espécie podem ser atribuídas, principalmente, a diferenças de época de colheita, tipo de solo, clima da região e umidade relativa do ar.

A composição química também pode variar em função de diversos fatores, entre eles as características ambientais e genéticas do espécime. Os compostos majoritários identificados no OE de $S$. montana L. foram timol $(15,47 \%)$, $\rho$-cimeno $(11,5 \%)$ e carvacrol $(9,81 \%)$ Resultados semelhantes foram descritos por Oliveira et al

Rev. Bras. PI. Med., Campinas, v.15, n.3, p.373-379, 2013. 
(2011) para o óleo de S. montana: timol (28,99\%), $\rho$-cimeno $(12,0 \%)$ e carvacrol $(10,71 \%)$. Para C. nardus, foram identificados os monoterpenos citronelal $(30,48 \%)$, citronelol $(14,32 \%)$ e geraniol $(17,12 \%)$. Os resultados encontrados por Oliveira et al. (2010) foram: citronelal $(34,60 \%)$, geraniol $(23,17 \%)$ e citronelol (12,9\%).C. limonia apresentou limoneno $(33,67 \%)$ em maior proporção, seguido pelo $\rho$-cimeno $(14,16 \%)$.Em óleos essenciais de plantas do gênero Citrus, o limoneno pode atingir $80 \%$ da composição total (Ladaniya, 2008). Alguns fatores como as características genéticas, a idade da planta e o ambiente, podem ser determinantes na quantidade dos constituintes (Natta et al., 2008). Segundo Gobbo-Neto \& Lopes (2007), a época em que a planta é coletada é um dos fatores de maior importância, visto que a quantidade e, às vezes, até mesmo a natureza dos constituintes ativos não é constante durante o ano. Aidade e o desenvolvimento da planta, bem como dos diferentes órgãos vegetais, também são de considerável importância e podem influenciar não só a quantidade total de metabólitos produzidos, mas, também, as proporções relativas dos componentes da mistura. Tavares et al.(2005) analisaram a composição do OE de três quimiótipos de Lippia alba e encontraram variação qualitativa e quantitativa entre os constituintes químicos.

No presente estudo verificou-se que houve atividade antimicrobiana dos OEs extraídos sobre ambas as bactérias. Na Tabela 1 podem-se observar os valores de halos inibitórios para cada bactéria e OE.

Staphylococcus aureus teve maior sensibilidade ao OE de C. limonia. A partir da concentração de $10 \%$ esse óleo mostrou-se mais eficiente que os outros. Já o óleo de S. montana teve atividade antimicrobiana somente a partir da concentração de 5\%. Cávar et al. (2008) apontam resultados diferentes aos desse estudo em relação a atividade antimicrobiana, em que o OE de $S$. montana foi mais eficiente contra $S$. aureus que a $E$. coli. Quanto maior a concentração utilizada, maiores foram os diâmetros dos halos inibitórios (Figuras 1 e 2), pois os componentes dos óleos apresentamse mais concentrados. Apesar de vários trabalhos relatarem a atividade antimicrobiana de plantas do gênero Citrus (Fischer \& Phillips, 2006), há poucos com informações da atividade antimicrobiana do OE de C. limonia. Pode-se atribuir o efeito antibacteriano dos óleos de C. nardus e C. limonia às altas quantidades de citronelal e limoneno, respectivamante. O mecanismo de ação desses compostos baseia-se principalmente em efeitos tóxicos na membrana celular, como a dissipação da força próton motiva, comprometendo a função no que diz respeito à permeabilidade seletiva (Sikkema et al., 1995).

Devido a natureza hidrofóbica e fenólica, timol e carvacrol, compostos majoritários do óleo de S. montana, interagem com a camada fosfolipídica da membrana citoplasmática e também com as e proteínas da membrana bacteriana, causando o vazamento do material celular, tais como íos, ATP e ácidos nucléicos (Burt, 2004).

Estudos têm confirmado a influência dos fatores ambientais como determinantes na ação antimicrobiana dos OE, a exemplo de Celiktas et al. (2007) que relacionaram o aumento da atividade antimicrobiana do OE de Rosmarinus officinalis em amostras coletadas na primavera. Moon et al. (2006) verificaram variação significante no tamanho dos halos de inibição quando testaram a atividade antimicrobiana do OE de diferentes amostras de Lavandula angustifólia frente aos mesmos microrganismos. A atividade antimicrobiana de um óleo pode ser, às vezes, bem diferente. Para uma

TABELA 1. Valores médios de halos de inibição $(\mathrm{mm})$ formados pela ação dos OEs de Satureja montana, Cymbopogon nardus e Citrus limonia Osbeck em diferentes concentrações.

\begin{tabular}{|c|c|c|c|c|c|c|}
\hline \multirow{2}{*}{$\begin{array}{l}\text { Bactérias } \\
\text { Concentrações (\%) }\end{array}$} & \multirow[b]{2}{*}{$\mathbf{s}$} & \multicolumn{2}{|c|}{ Staphylococcus aureus } & \multicolumn{3}{|c|}{ Escherichia coli } \\
\hline & & C & $\mathbf{L}$ & S & C & $\mathbf{L}$ \\
\hline DMSO $(0,2 \%)$ & 0,0 & 0,0 & 0,0 & 0,0 & 0,0 & 0,0 \\
\hline 1,5 & * & $1,00^{\mathrm{a}}$ & $3,33^{a}$ & $1,00^{a}$ & $1,00^{a}$ & $1,00^{\mathrm{a}}$ \\
\hline 2,5 & * & $1,00^{\mathrm{a}}$ & $3,66^{a}$ & $1,00^{\mathrm{a}}$ & $2,00^{a}$ & $2,00^{\mathrm{a}}$ \\
\hline 5,0 & $1,00^{\mathrm{a}}$ & $2,00^{\mathrm{a}}$ & $4,00^{\mathrm{a}}$ & $3,00^{a}$ & $2,33^{a}$ & $2,66^{a}$ \\
\hline 10,0 & $2,33^{a}$ & $3,00^{\mathrm{a}}$ & $8,33^{b}$ & $3,00^{a}$ & $3,33^{a}$ & $3,00^{a}$ \\
\hline 15,0 & $3,00^{\mathrm{a}}$ & $3,00^{a}$ & $9,00^{\mathrm{b}}$ & $4,66^{a}$ & $3,66^{a}$ & $3,66^{a}$ \\
\hline 25,0 & $4,66^{a}$ & $3,66^{a}$ & $9,33^{b}$ & $8,00^{c}$ & $4,00^{a}$ & $6,33^{b}$ \\
\hline 50,0 & $2,66^{b}$ & $4,00^{a}$ & $11,66^{b}$ & $15,66^{c}$ & $4,00^{a}$ & $10,0^{\mathrm{b}}$ \\
\hline
\end{tabular}

S: Satureja montana. C: Cymbopogon nardus.L: Citrus limonia. ${ }^{a, b, c}$ Teste Tukey a 95\% de significância para diferença de médias das zonas de inibição (mensuradas em milímetros), médias seguidas de mesma letra não diferem entre si significativamente na mesma linha* ausência de halo inibitório

Rev. Bras. PI. Med., Campinas, v.15, n.3, p.373-379, 2013. 


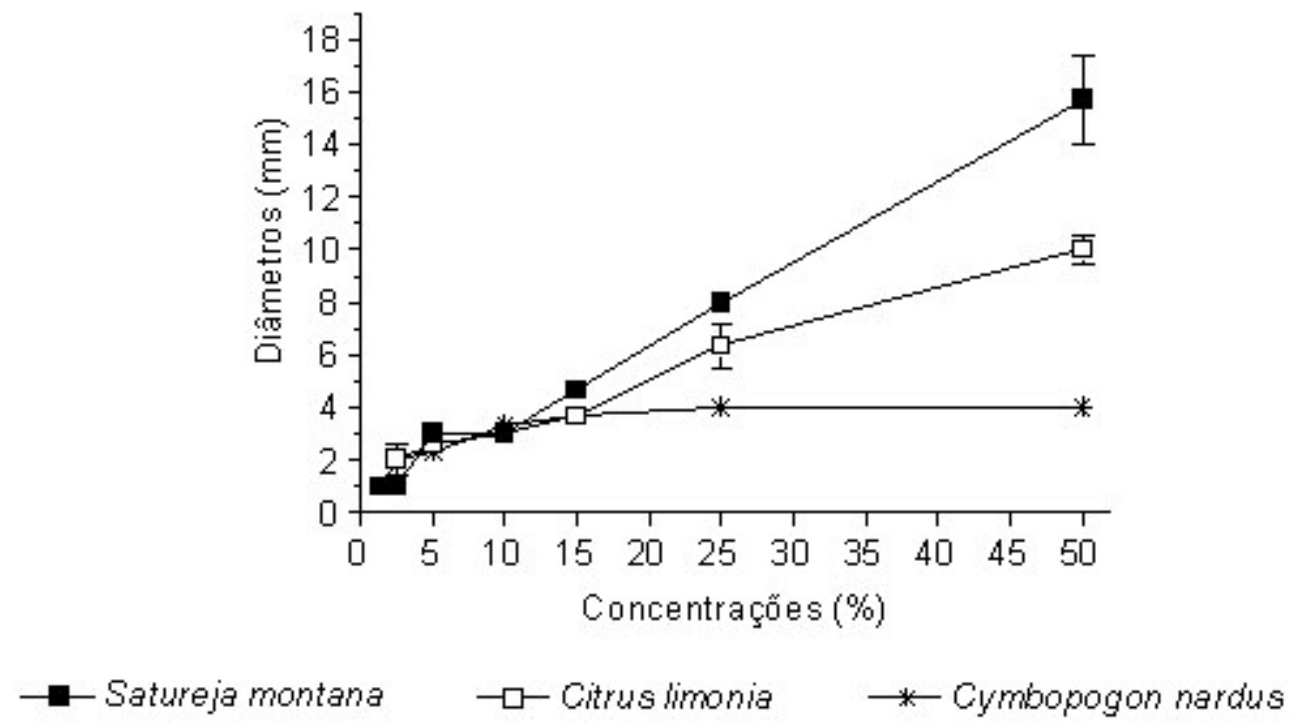

FIGURA 1. Zonas de inibição $(\mathrm{mm})$ em função das concentrações de diferentes óleos essenciais sobre Escherichia coli. Valores médios \pm Desvio padrão (barras).

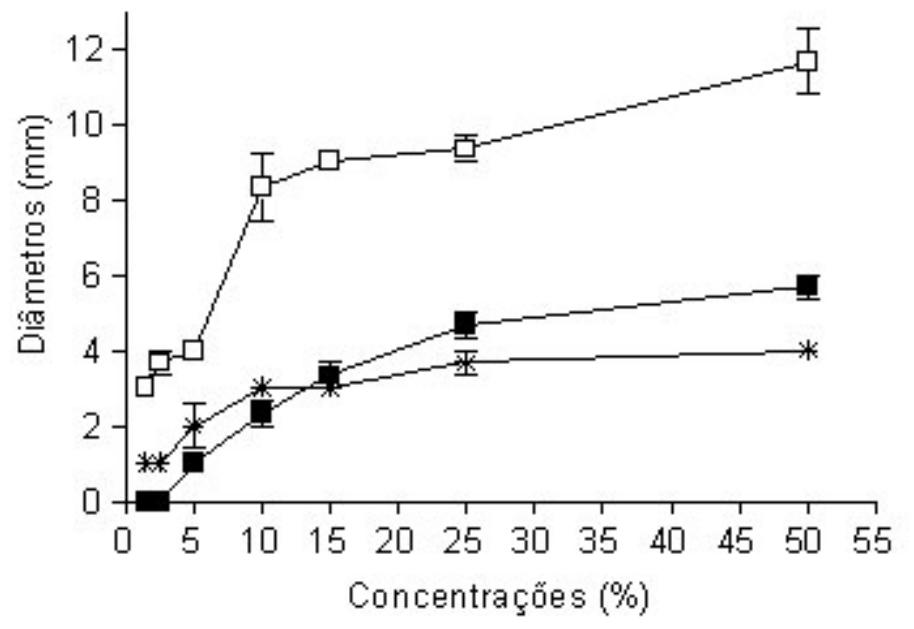

$\rightarrow$ - Satureja montana $\quad-\square-$ Citrus limonia $\rightarrow$ Cymbopogon nardus

FIGURA 2. Diâmetros em função das concentrações de óleos essenciais sobre Staphylococcus aureus. Valores médios \pm Desvio padrão (barras).

espécie em particular, por exemplo, os valores de CIM determinados para OEs de quimiotipos de Thymus vulgaris diferem quando se usam outras linhagens de um mesmo microrganismo (Janssen et al., 1987).

Nguefack et al. (2004) relatam maior atividade antibacteriana do óleo de $C$. citratus quando comparado a Z. officinales utilizando a metodologia de difusão em disco. No presente estudo, no qual também foi utilizada metodologia de disco-difusão, a maior ação inibidora foi obtida pelo óleo OE do $S$. montana contra $E$. coli e C. limonia para $S$. aureus. Diferenças entre resultados podem ocorrer mesmo quando se utiliza a mesma metodologia, pois existem também diferenças quanto à sensibilidade de linhagens de um determinado microrganismo frente a um mesmo produto antimicrobiano vegetal.

\section{CONCLUSÃO}

Os OEs apresentaram ação antibacteriana, sendo que $S$. aureus teve maior sensibilidade ao óleo essencial de limão e $E$. coli ao óleo de $S$. montana. Os resultados in vitro sugerem o uso potencial destes óleos como uma alternativa aos antimicrobianos e conservantes sintéticos. 


\section{AGRADECIMENTOS}

À FAPEMIG (Fundação de Amparo à Pesquisa do Estado de Minas Gerais) e a CAPES (Coordenação de Aperfeiçoamento de Pessoal de Nível Superior) pelo apoio financeiro na execução do projeto.

\section{REFERÊNCIA}

ADAMS, R.P. Identification of essential oils componets by gás chromatography/quadrupole mass spectroscopy. 4.ed. Carol Stream: Allured Publishing.2007, 803p.

CASTRO, L.O.; RAMOS, R.L.D. Principais gramímeas produtoras de óleos essenciais: Cymbopogoncitratus(DC.) Stapf, capim-cidró, Cymbopogonmartinii (Rox.) J. F. Watson, palmarosa, Cymbopogonnardus (L.)Rendle, citronela, Eluonuruscandidus (Trin.) Hack., capim limão, Vetiveriazizanioides (L.) Nash, vetiver. Porto Alegre: FEPAGRO, 2003, 23p.

CÁVAR, S.et al. Chemical composition and antioxidant and antimicrobial activity of two Satureja essential oils. Food Chemistry. v.111, 648-53,2008.

CELIKTAS, O.Y. et al. Antimicrobial activities of methanol extracts and essential oils of Rosmarinusofficinalis, depending on location and seasonal variations. Food Chemistry v.100,p.553-9, 2007.

ĆETKOVIĆ, G.S. et al. HPLC Screening of phenolic compounds in winter savory (Saturejamontana L.) extracts. Journal of Liquid Chromatography \& Related Technologies, v.30, p.293-306, 2007.

COSTA, A. G. Desenvolvimento vegetativo, rendimento e composição do óleo essencial de Patchouli após a adubação nitrogenada. 2008. 92p. Dissertação (Produção Vegetal) - Universidade Federal do Paraná, Curitiba.

CRAVEIRO, A. A. et al. Óleos essenciais de plantas do nordeste. Fortaleza: UFC, 1981, 210p.

FISHER, K.; PHILLIPS, C.A. The effect of lemon, orange and bergamot essential oils and their components on the survival of Campylobacter jejuni, Escherichia coli 0157, Listeria monocytogenes, Bacillus cereus and Staphylococcus aureus in vitro and in food systems. Journal of Applied Microbiology. v.101, 1232-40, 2006.

FRATERNALE, D.et al. Chemical composition and antifungal activity of the essential oil of Saturejamontana from central italy. Chemistry of Natural Compounds, v.43, 622-8, 2007.

GOBBO-NETO, L.; LOPES, N.P. Plantas medicinais: fatores de influência no conteúdo de metabolitos secundários. Química Nova, v.30, 374-81, 2007.

GUIMARÃES, L.G.L.et al. Influência da luz e da temperatura sobre a oxidação do óleo essencial de capim-limão (Cymbopogoncitratus(D.C.) Stapf). Quimica Nova. v.31, n.6, p.1476-80, 2008.

JANSSEN, A.M.; SCHEFFER, J.J.C; BAERHEIMSVENDSEN, A. Antimicrobial activity of essential oils: a 1976-1986 literature review. In: Aspects of the test methods. Plantas Medicinais. v.53, 395-98, 1987.
KIM, J.M.et al. Antibacterial activity of carvacrol, citral, and geraniol against Salmonella typhimurium in culture medium and on fish cubes. Journal of Food Science, v.60, 1364-8, 1995.

LADANIYA, M. Citrus fruit: biology, technology and evaluation. San Diego: Elsevier Academic Press, 2008, 558 p.

MARCO, C.A. et al.Características do óleo essencial de capim-citronela em função de espaçamento, altura e época de corte. Horticultura Brasileira, v.25, n.3, p.429-32, 2007.

MARTINS, E.R. et al. Plantas medicinais.Viçosa: UFV, 2003, 220p.

MILLEZI, A. F., et al. 2012a. In vitro antimicrobial properties of plant essential oils thymus vulgaris, cymbopogon citratus and laurus nobilis agains five important foodborne pathogens. Ciência e Tecnologia de Alimentos, pp. 0-0. Epub Feb 24, ISSN 0101-2061. http://dx.doi.org/10.1590/S010120612012005000021.

MILLEZI, A. F., et al. 2012b. Reduction of Aeromonas hidrophyla biofilm on stainless stell surface by essential oils. Brazillian Journal Microbiology, 44, 1, 73-80 (2013) w.

MOON, T.; WILKINSON, J.M.; CAVANAGH, H.M.A. Antibacterial activity of essential oils, hidrosols an plant extracts from Australian grown Lavandula spp. International Journal Aromatherapy, v.16, p.9-14, 2006.

NASCIMENTO, M.R.; STAMFORD, T.L.M. Incidência de Escherichia coli O157:H7. Revista de Higiene Alimentar. v.14, p.32-5, 2000.

NATTA, L. et al. Essential oil from five Zingiberaceae for anti food-borne bacteria. International Food Research Journal, v.15, n.3, p.337-46, 2008.

NCCLS (National Committee for Clinical Laboratory Standards). Methods for dilution antimicrobial susceptibility tests for bacteria that grow aerobically. Approved standard M7-A6, Wayne, Pa, USA, 2003.

NGUEFACK, J.; BUDDE, B.B.; JAKOBSEN, M. Five essential oils from aromatic plants of Cameroon: their antibacterial their antibacterial activity and ability to permeabilize the cytoplasmatic membrane of Listeria innocua examined by low cytometry. Letters in Applied Microbiology, v.39, p.395-400, 2004.

OLIVEIRA, M.M.M.et al. Disinfectant action of Cymbopogon sp. essential oils in different phases of biofilm formation by Listeria monocytogenes on stainless steel surface. Food Control, v.21, p.549-53, 2010.

OLIVEIRA, T.C.et al. Antimicrobial activity of Saturejamontana L. essential oil against Clostridium perfringens type $A$ inoculated in mortadella-type sausages formulated with different levels of sodium nitrite. International Journal of Food Microbiology. v.144, n.3, p.546-55, 2011.

SIKKEMA, J.; BONT, J.A.M.; POOLMAN, B. Interactions of cyclic hydrocarbons with biological membranes. Journal of Biological Chemistry. v.269, 8022-8, 1994.

PRIETO, J.M. et al. In vitro activity of the essential oils of Origanumvulgare, Saturejamontana and their main constituents in peroxynitrite-induced oxidative processes. Food Chemistry. v. 104, p.889-95, 2007.

PIMENTEL, F.A.et al. A convenient method for the determination of misture in aromatic plants. Quimica 
Nova, v.29, n.2, 373-5, 2006.

SPETHMANN, C.N. Medicina alternativa de A a Z. 7.ed. Uberlândia: Natureza, 2004, 392p.

SILVA, F.V.M. et al. Phytochemical profile and anticholinesterase and antimicrobial activities of supercritical versus conventional extracts of Saturejamontana. Journal of Agricultural and Food Chemistry. v.57, p.11557-63, 2009.

SIMÕES, C.M.O.; SPITZER, V. Óleos voláteis. In: SIMÕES, C.M.O.; SCHENKEL, E.P.; GOSMANN,
G.; MELLO, J.C.P.; MENTZ, L.A.; PETROVICK, P.R. Farmacognosia: da planta ao medicamento. 5.ed. Porto Alegre: UFRGS, 2004, p. 467-95.

SMITH-PALMER, A.; STEWART, J.; FYFE, L. The potential application of plant essential oils as natural food preservatives in soft cheese. Food Microbiology, v.18, 463-70, 2001.

TAVARES, E.S. et al. Análise do óleo essencial de folhas de três quimiotipos de Lippia alba (Mill.) N.E.Br. (Verbenaceae) cultivados em condições semelhantes. Revista Brasileira de Farmacognosia. v.15, p.1-5, 2005. 